\title{
Engineering properties of bitumen modified with bio-oil
}

\author{
Maisarah Rasman ${ }^{1}$, Norhidayah Abdul Hassan ${ }^{1, *}$, Mohd Rosli Hainin ${ }^{1}$, Ramadhansyah \\ Putra Jaya ${ }^{2}$, Haryati Yaacob ${ }^{1}$, Nurul Athma Mohd Shukry ${ }^{1}$, Mohd Ezree Abdullah ${ }^{3}$ and \\ Nurul Hidayah Mohd Kamaruddin ${ }^{3}$ \\ ${ }^{1}$ School of Civil Engineering, Faculty of Engineering, Universiti Teknologi Malaysia, 81310 Johor \\ Bahru, Johor \\ ${ }^{2}$ Faculty of Civil Engineering and Earth Resources, Universiti Malaysia Pahang, 26300 Gambang, \\ Pahang, Malaysia \\ ${ }^{3}$ Faculty of Civil and Environmental Engineering, Universiti Tun Hussein Onn Malaysia, 86400 Batu \\ Pahat, Johor, Malaysia
}

\begin{abstract}
The current high price of crude oils for bitumen production has led to various studies on the most economical way in replacing or reducing the amount of virgin bitumen as a binder in road pavement while increasing their pavement performance. The aim of this study is to investigate the effect of using bio-oil, particularly waste cooking oil, (WCO) on the engineering properties of bitumen. Both physical and rheological properties of the original bitumen and WCO modified bitumen were measured using penetration, softening point, viscosity, loss on heating and dynamic shear rheometer (DSR) tests. In this study, bitumen $80 / 100$ pen was modified with WCO at different percentages i.e. $1 \%, 2 \%$ and $3 \%$ by weight of bitumen. Based on the results, it was found that addition of WCO in virgin bitumen has softened the bitumen, thus increase the temperature susceptibility. In terms of rutting resistance, the addition of WCO up to $2 \%$ has produced modified bitumen with performance grade of PG 64 which is comparable to the original bitumen.
\end{abstract}

\section{Introduction}

High worldwide demand and increasing energy cost for petroleum have encouraged the development of alternative binders to modify or partially substitute the bitumen for asphalt pavement. The introduction and application of sustainable materials using non-petroleumbased binder in asphalt could have significant impacts on the economy as well as the asphalt pavement performance [1]. For pavement, the sustainability can be improved by minimizing the amount of energy consumption and use of recycled materials efficiently in the construction [2]. Bitumen is a viscous liquid or solid material, black or dark brown in color, which consists of a mixture of hydrocarbons of various compositions, possessing adhesive and water-proofing characteristics [3]. Bitumen is the most widely used material for constructing and maintaining roads in the world manufactured from selected crude oils

\footnotetext{
*Corresponding author: hnorhidayah@utm.my
} 
through a process of fractional distillation. For several years, the high price of the crude oils has affected the bitumen production, hence many researchers have shown great interest in bio-waste materials to minimize the dependencies on petroleum derived product. This approach has long been recognized and it has been proven that biomass or bio-waste products can be a great potential to produce bio-binder [4-6]. The utilization of some waste materials from other industries can minimize the bitumen consumption and improve the pavement durability [7].

Many countries including Malaysia have produced large quantities of waste cooking oil which is generated from household, restaurants, hotels, and food processing industries. In Malaysia, cooking oil production is largely originated from palm oil industries due to abundance of palm oil source. Most waste cooking oils were dumped in the open landfill and caused serious environmental problems by spreading horrible smells and carrying toxic liquid down through the soil, thereby contributing to the soil and water contamination. The efforts to overcome the high construction cost and reduce the environmental problems regarding the waste dumping issues have initiated the recycling practice of waste oil as an alternative solution to these problems [8]. Waste cooking oil (WCO) is a product of the frying activity at high temperatures which are usually performed in food industries, restaurants, hotels, and residences. It has been reported that the physiochemical properties of used cooking oil are different from those of unused oil in terms of density, kinematic viscosity, moisture content, flash point and acid value [9]. From the chemical test results as shown in Table 1, it was found that WCO is composed mainly of oleic acid $(43.67 \%)$, palmitic acid (38.35\%) followed by linoleic acid $(11.39 \%)$. The incorporation of WCO into pavement material is typically in liquid form, either blended with virgin bitumen for modification prior to mixing with aggregate, or directly poured into the heated aggregate or recycled asphalt pavement (RAP) [10].

Table 1. Chemical composition of waste cooking oil [10]

\begin{tabular}{lc}
\hline Fatty acid & Waste cooking oil $(\%)$ \\
\hline Oleic acid & 43.67 \\
Palmitic acid & 38.35 \\
Linoleic acid & 11.39 \\
Stearic acid & 4.33 \\
Myristic acid & 1.03 \\
T-Linoleic acid & 0.37 \\
Lauric acid & 0.34 \\
Linolenic acid & 0.29 \\
Cis-11 Eicosenoic acid & 0.16 \\
Heneicosanoic acid & 0.08 \\
TOTAL & 100 \\
\hline
\end{tabular}

Asli et al. [10] have conducted a study on the effect of WCO as a rejuvenator for aged bitumen on its physical properties such as the penetration, softening point and viscosity. Different groups of aged bitumen were blended by $1 \%, 2 \%, 3 \%, 4 \%$ and $5 \%$ of WCO at $130^{\circ} \mathrm{C}$ with a constant speed of $200 \mathrm{rpm}$. The results summarized that the aged bitumen group 50/60 needed $1 \%$, group 40/50 needed 3-4\% and group 30/40 needed 4-5\% as the optimum WCO content to achieve the original penetration value $80 / 100$. Meanwhile, the softening point and viscosity test indicated that there was no significant difference between the original bitumen and rejuvenated bitumen. Another study by Zargar et al. [11] reported that the penetration value of using 3-4\% of WCO into the aged bitumen group 40/50 showed comparable result with the original bitumen $80 / 100$. The viscosity test showed that 
the addition of 4\% WCO into the aged bitumen group 40/50 achieved almost the same viscosity as the original bitumen 80/100. Al-Omari et al. [12] investigated the possibility of using the waste vegetable oil (WVO) as a bitumen modifier and the effects of WVO addition on bitumen properties. Five different percentages $(1 \%, 2 \%, 4 \% 6 \%$, and $8 \%)$ of WVO by volume of the bitumen were used and it was found that the selection of suitable amount of WVO will improve most of the bitumen properties. It improved the ductility of the original bitumen, increased flash and fire point and reduced the viscosity while increasing fluidity for better workability at lower mixing temperature. Other effects of adding WVO include the increase in penetration and temperature susceptibility, decreasing the softening point which increases the softness of the bitumen and reduces the resistance against rutting.

Borhan et al. [13] evaluated the mechanical properties of modified asphalt mixture on cold-mix asphalt incorporating $0 \%, 20 \%, 25 \%$ and $30 \%$ of used cylinder oil (UCO) as a modifier. These samples were tested using Marshall stability, indirect tension test, static creep and dynamic creep tests. It has been reported that the presence of UCO decreased the Marshall stability, increased the design bitumen content, and reduced the stiffness of the asphalt mixture. Furthermore, adding UCO made the asphalt mixture more susceptible to permanent deformation and reduced the creep resistance ability due to the loss of cohesive and plastic properties of the asphalt mixture. In addition, Zaumanis et al. [14] reported that the fatigue resistance of aged bitumen can be significantly improved to the level of original bitumen by the addition of waste vegetable oil. Generally, a rejuvenator is needed to recover the necessary properties of aged binders. Aged bitumen in RAP is much stiffer and more susceptible to fatigue and thermal cracking failures, hence it is important to choose a rejuvenator that can reduce the viscosity of the aged bitumen to ensure the sufficient coating of aged bitumen to aggregated and enhanced mixture workability [14,15]. Therefore, this study aims to investigate the effect of using bio-oil particularly untreated $\mathrm{WCO}$ as an additive on the physical and rheological properties of bitumen based on laboratory testing.

\section{Experimental}

\subsection{Materials and sample preparations}

The materials used in this study were conventional bitumen with penetration grade 80/100 and waste cooking oil (WCO) as modifier. Waste cooking oil was collected from a food restaurant near Skudai, Johor. The $80 / 100$ pen bitumen was blended with different percentage of WCO i.e. $1 \%, 2 \%$ and $3 \%$ by weight of original bitumen. Table 2 shows the details of mass for each sample prepared in this study. The mixture was blended using a high shear mixer at a constant speed of $1000 \mathrm{rpm}$ for 1 hour at the temperature of $163^{\circ} \mathrm{C}$ until it was uniformly mixed.

Table 2. Total weight of modified bitumen material

\begin{tabular}{ccccc}
\hline Sample & WCO $(\%)$ & Original Bitumen $(\mathrm{g})$ & WCO $(\mathrm{g})$ & Total Weight $(\mathrm{g})$ \\
\hline 1 & 1 & 300 & 3 & 303 \\
2 & 2 & 300 & 6 & 306 \\
3 & 3 & 300 & 9 & 309 \\
\hline
\end{tabular}




\subsection{Laboratory tests}

\subsubsection{Penetration}

Penetration may be defined as the distance in tenths of a millimeter that a standard needle vertically penetrates a sample of material under known conditions of loading time and temperature. This test was used to evaluate the consistency of a bituminous material. The grade of semisolid and solid bituminous material is usually designated by the penetration. The bitumen sample was heated until it became sufficiently fluid and then poured into a penetration cup. The sample was cooled at room temperature for an hour and then placed in a water bath for another hour at $25^{\circ} \mathrm{C}$. The sample was then placed under $100 \mathrm{~g}$ load at constant temperature $25^{\circ} \mathrm{C}$ for $5 \mathrm{~s}$. A higher penetration value shows that the bitumen is softer while low value of penetration indicates that the bitumen is harder. Penetration Index (PI) was calculated to measure the temperature sensitivity of bitumen. Low PI indicates greater temperature susceptibility, while high PI indicates low temperature susceptibility [16].

\subsubsection{Softening point}

Softening point test was conducted to determine the temperature at which a material attains a particular degree of softness under specified conditions of test. As temperature increases, bitumen changes from solid to liquid, and the stiffness of bitumen will reduce. Higher grade bitumen has higher softening point compared to lower grade bitumen. In this test, the heated sampled was poured into rings and cooled at room temperatures for $30 \mathrm{~min}$. The sample was then immersed in the cold water at $5^{\circ} \mathrm{C}$ for $30 \mathrm{~min}$ before placed on the hot plate. A $3.5 \mathrm{~g}$ steel ball bearing was placed on each sample and heat was then applied to the beaker. The temperature of the water when the ball touches the base plate was recorded.

\subsubsection{Viscosity}

The degree of fluidity at the application temperature gives an impact on the ability of bituminous material to penetrate within voids and coat the aggregate. Viscosity test was conducted to determine the resistance to the flow of bitumen. It is also used to determine the viscosity of bitumen at high temperature range of mixing and paving. The viscosity test can be performed at various temperatures, but since manufacturing and construction temperatures are fairly similar regardless of the environment, the test was conducted at $135^{\circ} \mathrm{C}$ and $165^{\circ} \mathrm{C}$. Before conducting the test, the spindle, sample chamber, and viscometer environmental chamber were first preheated to $135^{\circ} \mathrm{C}$. The sample was heated until fluid enough to be poured into sample chamber and then brought to the test temperature of $135^{\circ} \mathrm{C}$ within approximately $30 \mathrm{~min}$. The test was then repeated with temperature of $165^{\circ} \mathrm{C}$.

\subsubsection{Loss on heating}

This test method measures the effect of heat on a film of semisolid asphaltic materials by determining the loss in mass after 5 hours of heating. Approximately $50 \mathrm{~g}$ of bitumen sample was heated at $163^{\circ} \mathrm{C}$ in a specified oven. The effect of heat was determined from changes incurred in physical properties measured before and after the oven treatment. The loss in weight was expressed as the percentage by weight of the original sample. 


\subsubsection{Dynamix Shear Rheometer (DSR)}

DSR is used to characterize the viscous and elastic behavior of bitumen from low to high temperatures at various frequencies. The operation of DSR is based on strain or stress measurements determined using the applied torque and angular deflection of a bitumen sample. In this test, a thin bitumen sample was used and sandwiched between two circular plates. The lower plate was fixed while the upper plate oscillated back and forth across the sample to create a shearing action. The sample was brought to the test temperature and the test started after the sample was at the desired temperature for at least $10 \mathrm{~min}$. The test was conducted at interval temperature of $6^{\circ} \mathrm{C}$ started from $46^{\circ} \mathrm{C}$ at a frequency of $10 \mathrm{rad} / \mathrm{s}$ $(1.592 \mathrm{~Hz})$ for 10 cycles. The values of complex modulus $\left(\mathrm{G}^{*}\right)$ and phase angle $(\delta)$ of the bitumen at each temperature were obtained and used as an indicator for rutting resistance.

\section{Results and Discussion}

\subsection{Penetration and Softening point}

Figure 1 shows the result of penetration, softening point and PI of the original and modified bitumen. Based on the figure, it can be seen that WCO modified binder can only be replaced up to $2 \%$ in order to achieve the equivalent penetration grade of 80/100 bitumen at the value of 95.6 pen. It was observed that the penetration value increases as the percentage of waste cooking oil into original bitumen increases. In addition, the penetration value for modified bitumen with 3\% WCO is higher than 100 pen, indicating that WCO has further softened the bitumen at higher degree. On the other hand, the softening point shows small difference between original and modified bitumen. Furthermore, it can be observed that all samples have PI values less than -2 considering that all samples are highly susceptible to temperature changes. 


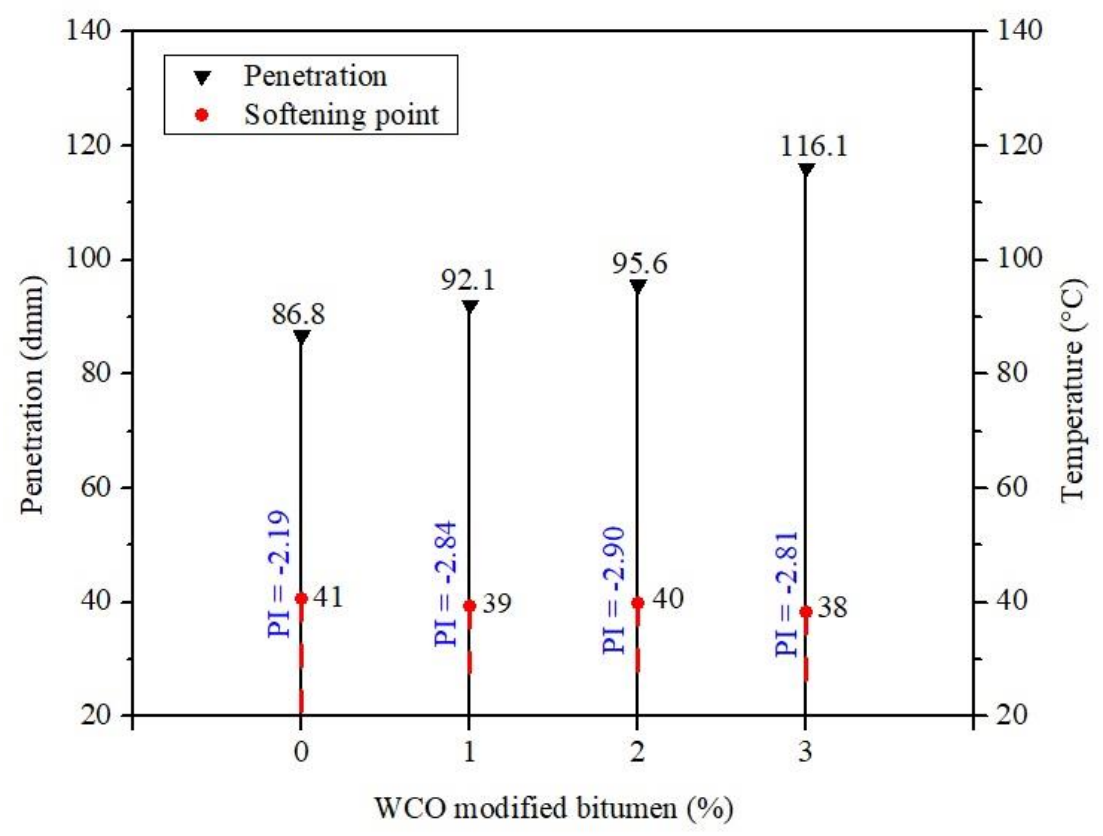

Fig. 1. Penetration, softening point and penetration index results.

\subsection{Viscosity}

The viscosity test result of original bitumen and modified bitumen at $135^{\circ} \mathrm{C}$ and $165^{\circ} \mathrm{C}$ is shown in Figure 2. Overall, the result clearly shows that the addition of WCO reduces the bitumen viscosity. At the temperature of $135^{\circ} \mathrm{C}$, the modified binder with $2 \%$ WCO achieved the same viscosity of the original bitumen while sample with $3 \%$ WCO has lower viscosity compared to original bitumen. It can be seen that the viscosity of original bitumen $80 / 100$ at $135^{\circ} \mathrm{C}$ is $0.3 \mathrm{~Pa}$.s which is more viscous than the addition of $3 \% \mathrm{WCO}$ with the viscosity of 0.2 Pa.s. Even though at $1 \%$ addition of WCO the viscosity was found to slightly increase to $0.4 \mathrm{~Pa}$.s, it decreased with the increase in WCO content. At $165^{\circ} \mathrm{C}$, the viscosity of original bitumen is $0.2 \mathrm{~Pa}$.s and decreased to $0.1 \mathrm{~Pa}$.s with the addition of WCO. Low viscosity means that the bitumen will be high susceptible to temperature changes, reduced potential of fatigue cracking under low temperature and improved workability. 


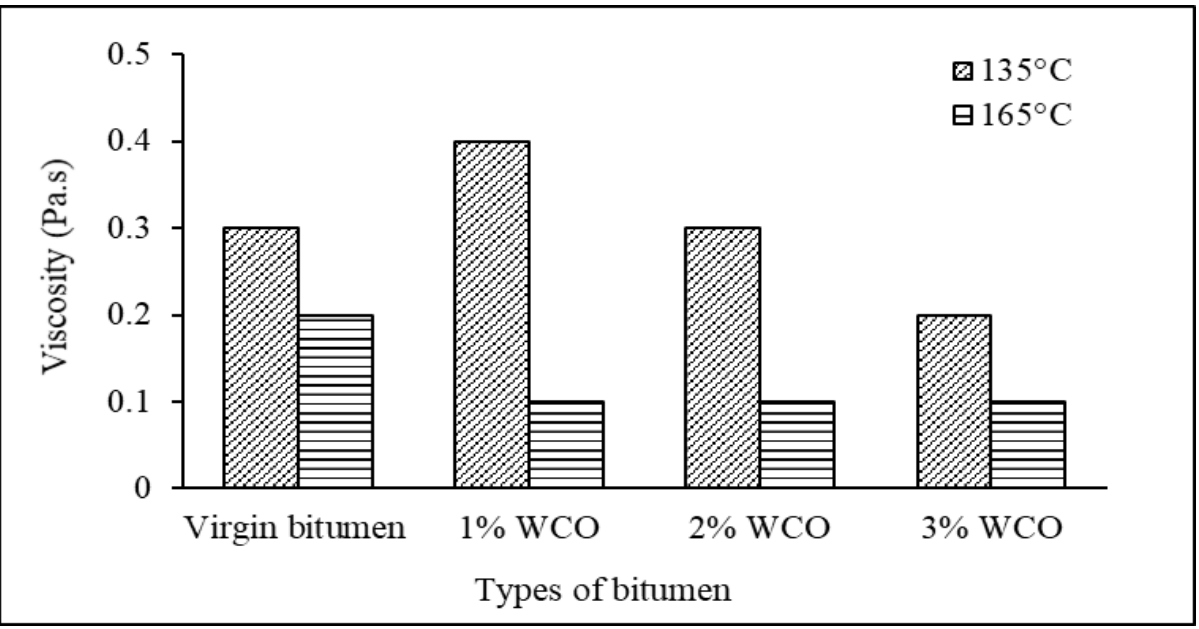

Fig. 2. Viscosity at the temperatures of $135^{\circ} \mathrm{C}$ and $165^{\circ} \mathrm{C}$.

\subsection{Loss on heating}

For bitumen $80 / 100$ penetration grade, percentage difference of weight loss must be less than $0.5 \%$ in order to be used in road construction. Table 3 shows the result of loss on heating for original bitumen and WCO modified bitumen. Based on the results, percentage of loss in mass for all modified samples is below specification which is less than $0.5 \%$. Hence, all the modified samples with WCO are acceptable according to the specification.

Table 3. Percentage difference of weight for loss on heating test

\begin{tabular}{cccc}
\hline Sample & $\begin{array}{c}\text { Weight before } \\
\text { heating }(\mathrm{g})\end{array}$ & $\begin{array}{c}\text { Weight after } \\
\text { heating }(\mathrm{g})\end{array}$ & \% Loss in mass $(\mathrm{g})$ \\
\hline $0 \%$ WCO & 116.9 & 116.8 & 0.09 \\
$1 \%$ WCO & 116.5 & 116.4 & 0.09 \\
$2 \%$ WCO & 300.0 & 299.8 & 0.07 \\
$3 \%$ WCO & 116.0 & 115.6 & 0.30 \\
\hline
\end{tabular}

\subsection{Rutting resistance}

Figure 3 shows the result of rutting resistance of original and modified bitumen. Based on Asphalt Institute, for unaged bitumen, the lowest limit of $\mathrm{G}^{*} / \sin \delta$ is specified at $1 \mathrm{kPa}$ [17]. The addition of $1 \%$ and $2 \%$ of WCO show comparable performance on rutting resistance to the original bitumen with failure temperature of $70^{\circ} \mathrm{C}$. In contrast, the sample with $3 \%$ WCO shows the lowest value of $\mathrm{G}^{*} / \sin \delta$ with the failure temperature of $64^{\circ} \mathrm{C}$. However, the $\mathrm{G}^{*} / \sin \delta$ for the asphalt binder decreases as the percentage of WCO increases to $3 \%$, which means the higher content of WCO has reduced the rutting resistance of the modified bitumen below the control sample. 


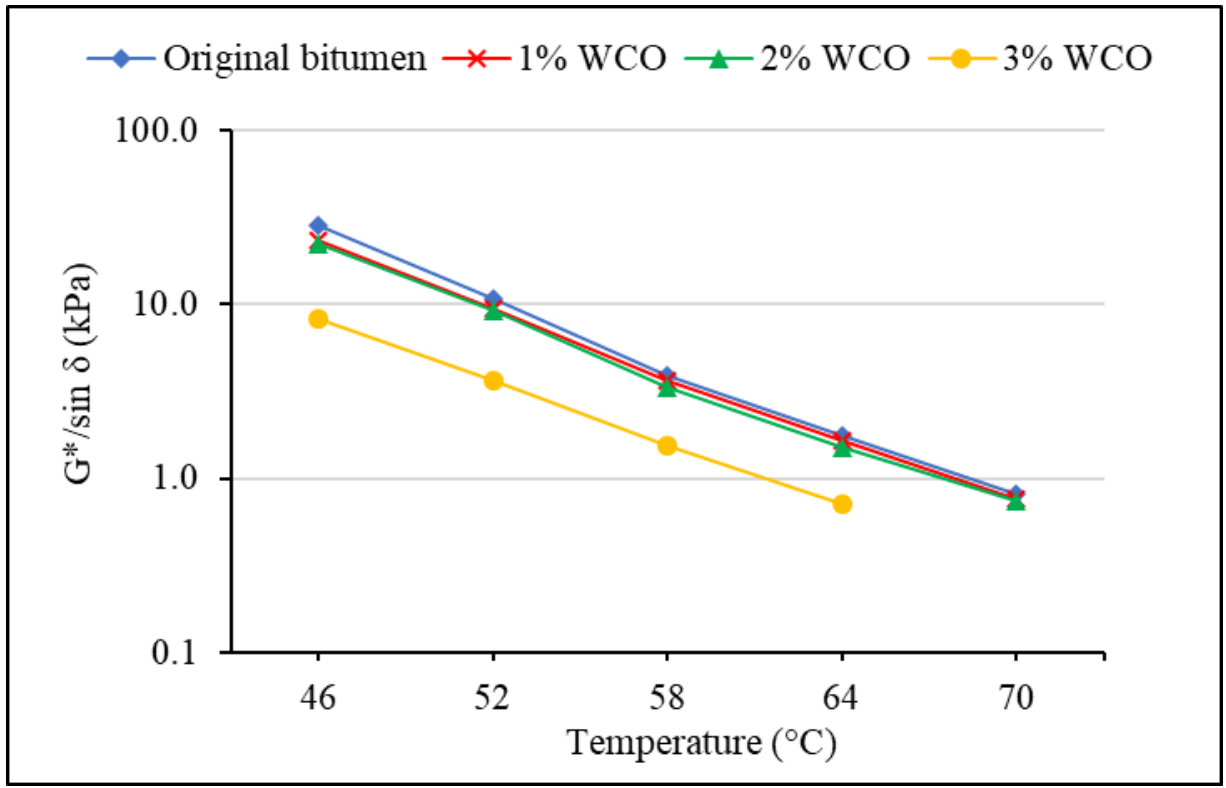

Fig.3. Rutting resistance of bitumen.

\section{Conclusion}

From the study on the effect of WCO on the engineering properties of bitumen, it can be concluded that the addition of WCO has led to having softer bitumen through penetration and softening point tests. Also, the use of WCO affects the temperature susceptibility of the bitumen and reduces the viscosity of the modified bitumen. Low viscosity indicates that the bitumen has low internal friction and resistance to flow. By adding up to $2 \% \mathrm{WCO}$ in the bitumen, the binder rutting resistance is comparable to the unmodified bitumen. The loss of heating value of original and modified bitumen was found less than $0.5 \%$, which is acceptable according to the specification.

The support provided by Malaysian Ministry of Higher Education (MOHE), Universiti Teknologi Malaysia (UTM) in the form of a research grant number Q.J130000.2522.19H82 and R.J130000.7822.4F867 for this study is very much appreciated.

\section{References}

1. Peralta J, Williams R C, Marjorie R and Silva H M R D. Alternative Binders for Sustainable Asphalt Pavements Development of rubber-modified fractionated bio-oil for use as noncrude petroleum binder in flexible pavements Transportation Research Circular NumberE-C165 August Washington DC pp 23-36 (2012)

2. Zakaria R, Seng F K, Majid M Z A, Zin R M, Hainin M R, Puan O C, Yaacob H, Derin N, Ainee F, Hamzah N, Balubaid S O, Mazlan A N, Ismail M A, Yazid Y S, Rooshdi R R R M and Moayedi F. Energy efficiency criteria for green highways in Malaysia. Jurnal Teknologi 65 (3) 91-95 (2013) 
3. Rahman M T, Aziz M M A, Hainin M R and Bakar W A W A. Impact of bitumen binder: Scope of bio-based binder for construction of flexible pavement. Jurnal Teknologi 70 (7) 105-9 (2014)

4. Yang X, You Z and Dai Q. Performance evaluation of asphalt binder modified by biooil generated from waste wood resources International Journal of Pavement Research and Technology 6 (4) 431-9 (2014)

5. Mohammad L N, Elseifi M, Cooper III S B, Challa H and Naidoo P. Laboratory evaluation of asphalt mixtures containing bio-binder technologies. Journal of the Transportation Research Board 2371 58-65 (2013)

6. Mills-Beale J, You Z, Fini E, Zada B, Lee C H and Yap Y K. Aging influence on rheology properties of petroleum-based asphalt modified with bio-binder. Journal of Materials in Civil Engineering 26 (2) 358-66 (2014)

7. Sun Z, Yi J, Huang Y, Feng D and Guo C. Properties of asphalt binder modified by bio-oil derived from waste cooking oil. Construction and Building Materials 102 496504 (2016)

8. Azahar W N A W, Bujang M, Jaya R P, Hainin M R, Mohamed A, Ngadi N and Jayanti D S. The potential of waste cooking oil as bio-asphalt for alternative binder an overview. Jurnal Teknologi 78 (4) 111-6 (2016)

9. Ullah Z, Bustam M A and Man Z. Characterization of waste palm cooking oil for biodiesel production. International Journal of Chemical Engineering and Applications 5 (2) 134-7 (2014)

10. Asli H, Ahmadinia E, Zargar M and Karim M R. Investigation on physical properties of waste cooking oil - rejuvenated bitumen binder. Construction and Building Materials 37 398-405 (2012)

11. Zargar M, Ahmadinia E, Asli H and Karim M R. Investigation of the possibility of using waste cooking oil as a rejuvenating agent for aged bitumen. Journal of Hazardous Materials 233-234 254-8 (2012)

12. Al-Omari A A, Khedaywi T S and Khasawneh M A. Laboratory characterization of asphalt binders modified with waste vegetable oil using Superpave specifications. International Journal of Pavement Research and Technology In press (2017)

13. Borhan M.N, Suja F, Ismail A and Rahmat R A. Used cylinder oil modified cold-mix asphalt concrete. Journal of Applied Sciences 7 (22) 3485-91 (2007)

14. Zaumanis M, Mallick R B and Frank R Use of rejuvenators for production of sustainable high content RAP hot mix asphalt. 28 $8^{\text {th }}$ International Baltic Road Conference Vilnius Lithuania (2013)

15. Shen J, Amirkhanian S and Miller J A. Effects of rejuvenating agents on Superpave mixtures containing reclaimed asphalt pavement. Journal of Materials in Civil Engineering 19 (5) 376-84 (2007)

16. Read, J and Whiteoak, D. The Shell Bitumen Handbook, Shell Bitumen Thomas Telford Publishing, London, UK, $5^{\text {th }}$ edition (2003)

17. Asphalt Institute. Superpave Performance Graded Asphalt Binder Specification and testing. Superpave Series No 1. Asphalt Institute, Lexington, KY, USA. (1997) 